are not implicated. There is a small, dark-coloured swelling, like a nævus, on the right side of the tongue. He had never noticed it himself, and does not know when it came. Has always been a healthy, sober man; has a florid countenance, but is somewhat emaciated; says he has been getting thin these six months. Last January he had a fit, which rendered him insensible for a few minutes; this occurred after a hard day's work, but he soon recovered; there was sickness, but no other illness. There is a little emphysema at the lower part of the right lung, otherwise the lungs are healthy. Heart's sounds good; but the hand discovers a rubbing sensation, as of old adhesions or effused lymph, on the surface of the pericardium. Has a hernia of the left side. Bowels regular; urine natural; tongue clean; good spirits generally; sleeps and eats well.

Nov. 4th. - Considerable hæmorrhage last night. Mr. Wakley now deemed it necessary, as a remote chance of saving the man's life, to amputate the arm at the shoulder-joint. It was evident that he must sink, from hæmorrhage, in a very short time, if the operation were delayed; accordingly, Mr. Wakley operated this day at half-past two o'clock. He formed his largest flap from the deltoid muscle, in order to avoid the chance of being obliged to keep diseased skin to cover the internal flap, the tumour extending very high up towards the axilla. Very little blood was lost. The arteries were perfectly healthy. The amputation occupied less than a minute. Ether was used, and again appeared to be very perfect in its effects. Ordered, opium and brandy.-Three P.M. : No hæmorrhage; pulse 100; doing well.-Ten P.Mr.: Ordered one grain of morphia.

5th.-Slept well all through the night; tongue furred; pulse 100, compressible ; bowels confined. Castor oil, one ounce; broth; eggs ; camphor mixture and opium; two ounces of brandy ordered at night.

6th.-Pulse 102, soft; bowels well opened; passed a good night; very small quantity of venous hæmorrhage last night.

7 th. - Sleeps and eats well; bowels free. Port wine, five ounces.

8th.-The stump was dressed to-day; the healing process was going on successfully, excepting that there was a small slough at the inner side of the wound, and the discharge from that part was thin; he is in good spirits; eats and sleeps well; Is sitting up. Repeat mixture ; meat and wine.

10th.--Bowels purged. Ordered, an egg, arrowroot, milk, and beef-tea.

11th.-Bowels still relaxed. Ordered, a mixture composed of aromatic confection, compound spirit of ammonia, and compound sulphuric ether.

12th.-Bowels more composed; has passed a good night; the discharge is thick laudable pus.

17th. - Ligatures came away yesterday; healing process going on favourably; sleeps and eats well; bowels regular; tongue clean.

Nov. 29th.-Has not had one unfavourable symptom; stump healing; discharges thick laudable pus. Ordered, meat, and porter, one pint.

Dec. 11th.- The wound has continued to heal regularly; the granulations are rather pale and flabby, and have required, occasionally, touching with caustic; the discharge is slight and healthy.

13th.-The wound is perfectly healed. The patient is much stouter than before the operation.

15th.-The man appears to be quite well in all respects.

\section{Qriónal 坊apers.}

\section{A MEDICAL HISTORY OF}

\section{SIX CASES OF POISONING BY ARSENIC.}

\section{By ROBERT BARNES, M.B.}

$$
\text { LECTURER ON FORENSIC MEDICINE. }
$$

ON the 30th of May, 1847, Mr. Abercromby, of Kensall New Town, was summoned, at half-past two P.M., to see the family of Thomas Hickman. The family, consisting of nine persons, had all been dining off rhubarb pudding, and all had been seized with nansea or vomiting during the meal. Mr. Abercromby took notice of the following symptoms:-All complained of a feeling of sickness, and all vomited immediately after eating of the pudding, excepting the father, who vomited soon after Mr. Abercromby saw him. The infant, aged one year and five months, was in a state of collapse. In a short time, the patients all complained of more or less of pain in the stomach, and burning in the throat-_ "dryness" was their: own expression. Copions vomiting continued, followed by incessant thirst, and great prostration of strength. The father exhibited great anxiety of countenance.

Mr. Abercromby administered a mixture of white of egg, flour, and milk, to all by the teacupful, which was almost immediately, in all the cases, rejected. The dose was renewed, at short intervals, for about an hour. The prostration, however, increased, and Mr. Abercromby sent to request my assistance. On my arrival, at twenty minutes past four P.Mr., I observed the following symptoms:-The father, aged thirtythree, was pale, exhibiting great prostration and anxiety of countenance, and without being unconscious, some degree of stupor; he complained of some pain (not great) in the stomach; the palse was quick, and depressed in character. The two women-the mother and her sister-did not exhibit any great prostration; the pulse in both was quick, but pretty strong. The mother was flushed in the face, and did not complain of much pain. The eldest boy, aged twelve, did not appear to suffer anything particular; he was a little flushed. The five remaining children-all under nine years of age-were all greatly prostrated; their countenances were pallid and anxious; pulses scarcely perceptible; and their extremities cold. Ore boy-James, aged nime-complained, in addition, of severe pain in the stomach and bowels, and drew up his legs. The infant was profoundly collapsed; the pupils acted under alternations of light and shade.

Mr. Abercromby, Mr. Brown, and myself, concurred in administering a mixture of ipecacuanha and sulphate of zinc, in water, to all. All vomited freely in consequence. A mixture of hydrated sesquioxide of iron, in milk, was then freely given. All the patients took the remedies offered readily, excepting the man, who, from his great prostration, was with difficulty prevailed on to take the sesquioxide of iron.

After this, the vomiting continued at intervals; and to counteract the increasing prostration, brandy, ether, and ammonia, were administered, at intervals, by $\mathbf{M r}$. Abercromby and Mr. Brown; but with little effect, for five children succumbed in the course of the night, as follows:-

James, aged nine years, sunk into perfect collapse, with blue lips, cold extremities, and no pulse, and died at six P.M. John, aged three years, died in a similar manner, at halfpast seven P.M.

Henry, aged one year and five months, died convulsed, at nine P.M.

Mary-Ann, aged four years and ten months, died in like manner as James, at half-past ten P.M.

Harriet, aged six years, died at half-past eleven P.I.

On the following day, at nine A.M., the father had fallen into greater prostration; the pulse was scarcely perceptible; the body was generally cold and clammy; hands and feet very cold; did not complain of much pain; had been freely purged; the vomiting abated about midnight; after which time he had retained fluids, (milk and linseed tea.) He had had a blister to the stomach, and had taken opium and ether at intervals.

The two women did not appear to suffer much; the tongues were red and clean at points, and round the margin, and presented a slight, white, creamy fur in the middle. The sister complained of headach; was fiushed; pulse 100, rather strong; skin warm and moist; thirst; had passed no water; had been purged; some tea taken in the morning remained on the stomach. The mother was less feverish than the sister; had passed water.

The eldest boy presented no remarkable symptom.

The man died at noon, no reaction having occurred. He retained his consciousness to the last.

On the third day, at eight A.I., the sister still complained of headach; no pain at the stomach or throat, but sometimes violent throbbing in the stonach; the pulse was full, 90 ; face flushed; had passed some water, which was scantr, and very red; has had leeches to the temples. The symptoms all gave way in a few days, and she perfectly recovered.

The mother and eldest boy may be said to have recovered on this, the third day.

I have collected the results of the post-mortem examinations of the six patients who died, into a tabular arrangement. Dr. Chowne, Mr. Abercromby, Mr. Brown, and myself, were present at all the examinations.

(See the table in the following page.) Anatysis of Autopsies.

1. All showed marks of inflammation in some part of the intestinal canal

2. No one of the four examined presented distinct inflammation of the cesophagus. 


\begin{tabular}{|c|c|c|c|c|c|c|}
\hline $\begin{array}{l}\dot{\overrightarrow{0}} \\
\dot{\vec{b}}\end{array}$ & . & & & 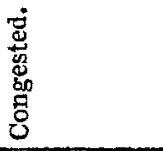 & & 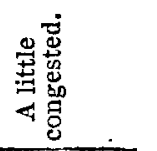 \\
\hline 窎 & 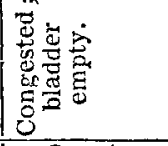 & 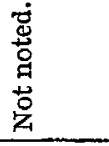 & 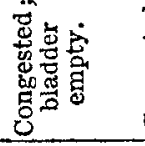 & 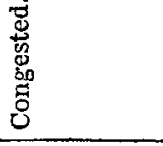 & 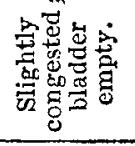 & 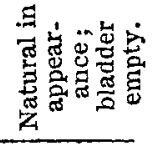 \\
\hline 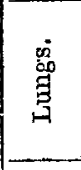 & 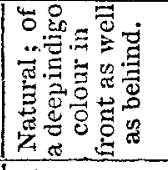 & 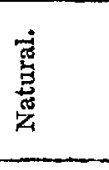 & 营 & 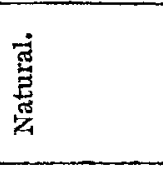 & 宽 & 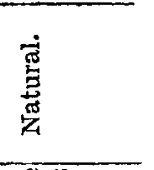 \\
\hline 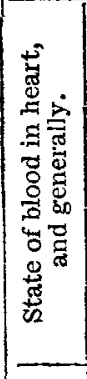 & 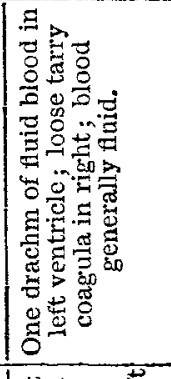 & 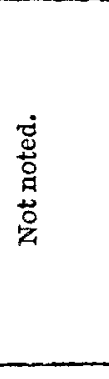 & 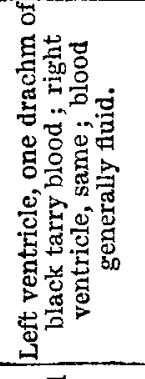 & 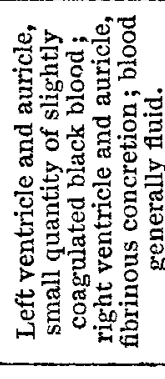 & 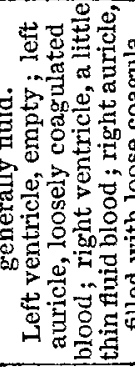 & 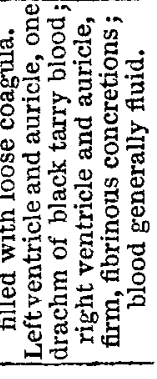 \\
\hline 莣 & 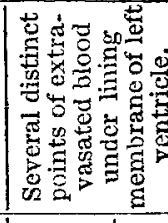 & : & 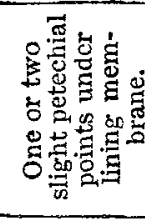 & : & $\begin{array}{l}: \\
:\end{array}$ & $\begin{array}{l}: \\
: \\
:\end{array}$ \\
\hline 焉 & 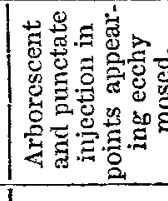 & & 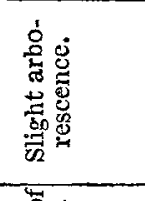 & $\begin{array}{l}: \\
: \\
: \\
\end{array}$ & $\begin{array}{l}: \\
: \\
\end{array}$ & $:$ \\
\hline $\begin{array}{l}\stackrel{\Xi}{\circ} \\
\stackrel{0}{8}\end{array}$ & 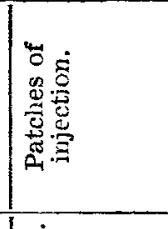 & $\begin{array}{l}: \\
: \\
:\end{array}$ & 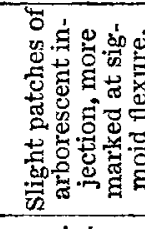 & 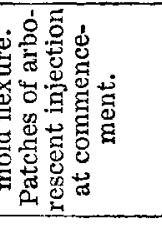 & 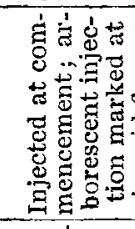 & 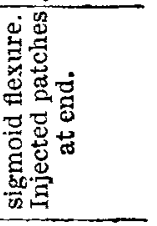 \\
\hline 窇 & : & 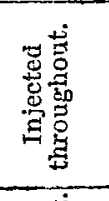 & 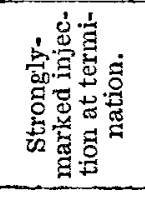 & $\frac{\dot{0}}{\tilde{\sigma}}$ & 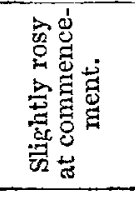 & $\frac{\dot{0}}{\tilde{\sigma}}$ \\
\hline$\underset{\mathscr{\Xi}}{\stackrel{\Xi}{\Xi}}$ & 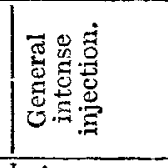 & 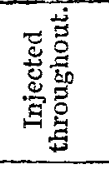 & 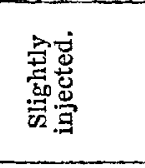 & 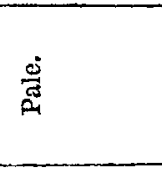 & 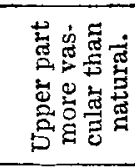 & 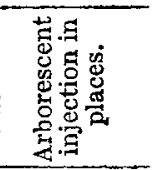 \\
\hline 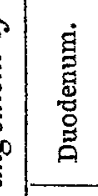 & 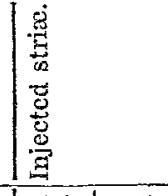 & 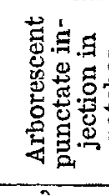 & 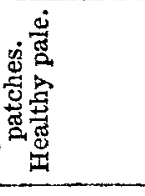 & 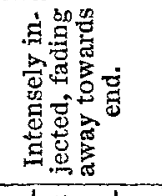 & 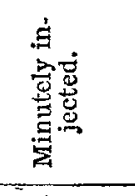 & 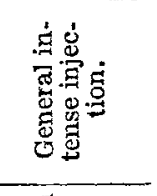 \\
\hline 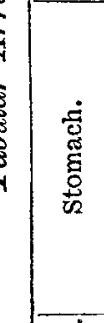 & \multicolumn{2}{|c|}{ 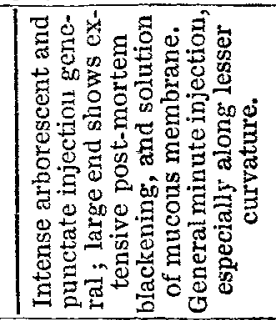 } & 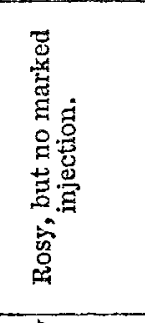 & 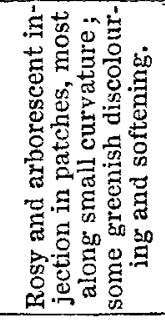 & 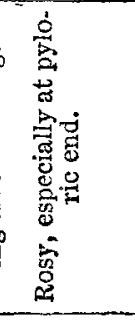 & 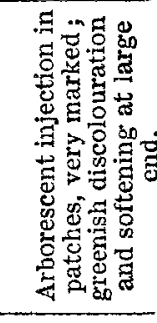 \\
\hline 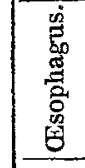 & 语 & 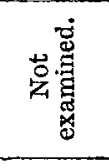 & 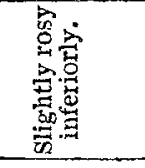 & 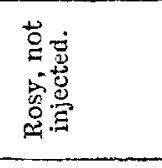 & 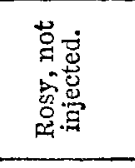 & $\frac{\dot{s}}{\pi \Phi}$ \\
\hline & 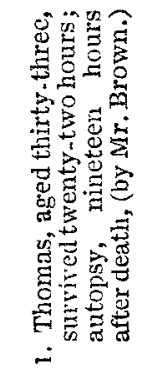 & 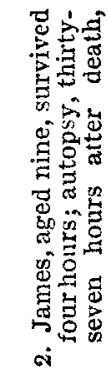 & 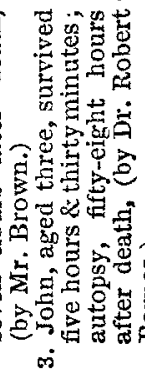 & 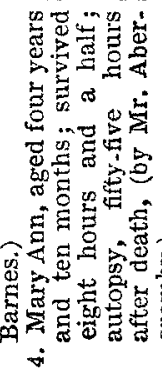 & 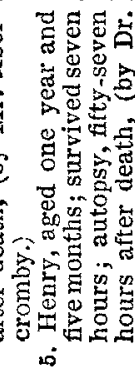 & 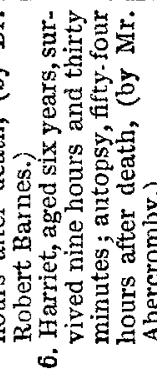 \\
\hline
\end{tabular}

3. In five cases there was inflammation, more or less intense, of stomach. The inflammation was most intense in Thomas, who survived the longest, and in James, who died first.

4. In five cases the duodenum was inflamed; in three cases intensely.

5. In five cases the jejunum was injected.

6 . The ileum was intensely inflamed througlout in one case; at the termination only, in another.

7. The colon was injected in five cases.

8. The rectum was decidedly injected in one case only, that of Thomas, who survived the longest.

9. The heart presented well-marked ecchymosed spots under the lining membrane of left ventricle in one case only.

10. 'The blood in the cavities of the heart was generally observed to be black, and of a tarry consistence, with a tendency to loose coagulation in three cases, and formation of fibrinous concretions in the right cavities, in two cases. The blood generally, in the large veins, was thin and fluid.

11. The lungs in no case presented anything remarkable.

12. The kidneys were observed to be more or less congested in four cases, and the bladder was observed to be empty in four cases.

13. The liver appeared unduly congested in two cases.

The following deductions, arising from observation of the symptoms and post-mortem appearances,also claim attention:-

14. No case presented any evidence of corrosion or ulceration; but Dr. Williams pointed out, in the stomachs of the four children which I exhibited to the Pathological Society, enlargement of the glands.

15. Although the cesophagus showed no injection on examie nation, the dryness and thirst during life would indicate some irritation.

16. The man who exhibited irritation of the rectum lived twenty-two hours, and had been freely purged; the children, who all died within nine hours and a half, showed no irritation of the rectum, but more or less of the colon, excepting one, who survived only four hours. The appearance of irritation, therefore, shows a distinct relation to the progress of the poison along the intestinal canal.

17. The slight congestion of the liver noted in two cases, the congestion of the kidneys noted in four cases, the empty bladder in four cases, and the want of micturition for some time, and subsequent difficult micturition, in one case which recovered, indicate that the liver and the kidneys were the vice by which the system endeavoured to get rid of the absorbed poison. It is to be regretted that the urine was not examined for arsenic: I had desired it to be saved, but it was thrown away.

18. The general character of the symptoms may be summed up as follows:-The first symptom observed by the patients was a feeling of sickness, followed by vomiting directly after partaking of the poisoned food. The vomiting was delayed for twenty minutes or half an hour in one case; pain in the stomach, burning and "dryness" in the throat soon supervened; urgent vomiting, incessant thirst, great prostration of strength, and intense anxiety, soon came on; the infant sank into collapse within half an hour; and in all the cases which ended fatally, anxiety and pallor of countenance, cold extremities, and feeble, almost imperceptible pulse, were observed within two hours of taking the poison. One boy, who died within four hours, complained throughout of violent pain in the bowels, and drew up his legs. All preserved consciousness to the last, excepting the infant; the pupils continued to act; and in all cases the pupils were dilated at death. The children gradually fell into deeper collapse, and sank, the last surviving nine hours and a half. One child-the infant-died convulsed; and one showed contraction of the fingers, with the thumbs turned inwards, after death. In the three cases which survived, the chief symptoms were, burning of the throat, vomiting, and anxiety, but no marked prostration at any period. Some degree of febrile reaction came on twelve hour's after, accompanied with slight gastritis, and congestion of the kidneys, in one case; the conjunctivæ were not affected in any case; nor did any paralysis or other nervous affection appear. I must not omit to state, that the different effect of the poison upon the six who succumbed, and the three who recovered, may be accounted for by the fact, that the arsenic was unequally diffused through the pudding, the chemical analysis having shown that some parts of the pudding contained a much larger proportion than others. It is probable, therefore, that the survivors partook of those parts of the pudding which contained but little arsenic.

In our reflections ipon the symptoms and post-mortem appearances above described, it may not be unimportant to 
take into consideration the remedies which had been givenviz., ipecacuanha, sulphate of zinc, and oxide of iron.

In the above relation, I have not thought it necessary to minutely detail the chemical analysis, as it presented no point of especial interest. Arsenic was obtained in abundance in the crystalline and metallic form, both from the pudding and the vomited matter, by myself and Mr. Abercromby. The contents of the stomachs of Harriet, John, Mary-Ann, and Henry, yielded no trace of arsenic. Mr. Brown obtained evidence of the presence of arsenic in the contents of the stomachs of Thomas and James.

It is rarely that the deplorable opportunity occurs of studying the effects of arsenic upon so large a scale, and of contrasting the action of the poison on so many different individuals. On account, therefore, of the mass of facts which these cases furnish, I think that their medical history ought to be recorded.

Gloucester-terrace, H5de-park, Dec. 1847.

\section{ADMINISTRATION OF CHLOROFORM IN CASES OF DIFFICULT PARTURITION; DELIVERY COMPLETED WITHOUT PAIK.}

By EDWARD W. MURPHY, A.M., M.D., PROFESSOR OF MIDWLFERY TO UNIVERSITY COLLEGE, LONDON,

The interest excited by Professor Simpson's discovery of the anodyne power of the new agent, chloroform, (possessing, as it seems to do, many advantages over sulphuric ether,) has induced me to bring forward the following cases sooner than I should otherwise have done, because they illustrate its effect in a very remarkable manner.

On November 25 th, 1847 , I was summoned to see a patient in protracted labour, who had received a letter from University College Hospital, to be attended to when she was confined. On examination, I found the pelvis greatly contracted in its antero-posterior measurement, and concluded that perforation must ultimately be had recourse to in order to deliver her. I determined on testing the value of chloroform, and submitting her to its influence when I should be obliged to operate. The better to accomplish my object, that this narcotic should be most efficiently administered, and its effects carefully observed, I requested Dr. Snow (who is perfectly conversant with the management of ether) to give me his assistance, and to take charge of the administration of the chloroform: in the kindest manner he consented to do so, and thus removed from my mind any fear of failure in using this agent. The following is the history of the case, the operation, and the results:-

Contracted pelvis two inches and a half from pubis to sacrum; delivery by perforation after thirty-nine hours' labour.

CASE 1.-E. G-, aged thirty-six, living in Grove-street, Camden-town; is of moderate height and delicate appearance; from infancy she had never been in perfect health. She states that her father died of consumption; that she had sixteen brothers and sisters, all of whom, with one exception, died in their childhood between two and a half and five and a half years of age; her only surviving sister has delicate health, but its cause is not stated.

E. G-, when a child, suffered from small.pox, measles, and hooping-cough. The catamenia did not appear until she was nineteen years of age, and was always very irregular; she had been much subject to leucorrhoea, and about twelve years since a calculus was removed from the bladder, which caused her much suffering. At twenty-one years of age she was taken in labour with her first child, ( $a$ boy,) which, she says, was "a cross-birth." Her labour lasted from Saturday morning till Monday, at one o'clock P.M., about fifty-six hours; the child was still-born. Two years after this, premature labour came on about the middle of the seventh month, which continured from Thursday to Saturday morning: she was delivered of a boy, also dead. After an interval of two years more, she was confined of her third child, (a boy,) and labour lasted from Saturday morning to Tuesday, at one P.M., perhaps eighty hours: the boy was born dead. She was not again pregnant for nearly three years, and about three years and a half from her last confinement, she was delivered of a girl, (still-born,) after labour that continued from Friday night to Monday morning, at six o'clock A.M., about fifty-six hours. Two years afterwards she was delivered of a boy, (dead,) being " two whole days in labour." In two years more she was delivered of her sixth child. She was in labour from the morning of
February 28th, 1845, to the evening of March 2nd, (sixty hours, ) and was then delivered, by the forceps, of a boy, (stillborn.) Thus all her labours were extremely protracted, all her children still-born, and, with one exception, all males.

In her seventh pregnancy she sought our assistance when labour was approaching. It commenced Nov. $21 \mathrm{th}$, at six o'clock A.M.; the waters escaped at half-past ten, and the pains continued regularly during that day and night. A bout eleven o'clo.k on the following day I saw her, and found the os uteri nearly dilated, the vagina moist and cool, the head above the brim of the pelvis, the conjugate measurement of which was only two inches and a half. I felt satisfied that the head of the child conld not descend into the pelvis, but allowed labour to proceed, in order to ascertain whether it might enter the brim sufficiently to be extracted by the forceps. I returned again in the evening, having previously apprized Dr. Snow and some other friends of my intentions.

Nov. 25th.-Half-past eight o'clock P.M.: She had been now more than thirty-eight hours in labour, and had very strong and regular pains during the day, but no alteration was made in the position of the head; a large quantity of urine was drawn off by the catheter, and everything prepared for her delivery. At twenty minutes before nine o'clock, Dr. Snow proceeded to administer chloroform. At first the woman made considerable resistance to it, from a misapprehension of its purpose; she believed that it was intended to put her to sleep only, and that after she awoke we were to deliver her; this prevented its effects being produced in the quiet manner that is stated. She soon, however, fell into a dreamy sleep, snoring sometimes, and sometimes talking incoherently; this subsided into a deeper and more tranquil sleep. Before inhalation the pulse was 120 ; during its administration, it rose to 140 , and again fell to 135 and 130.

Soon after she commenced to inhale, I perforated the head with Naegele's perforator. When the instrument was withdrawn, the bones so strongly overlapped, that it was very difficult to introduce the crotchet; when it was accomplished, and a secure purchase obtained, I endeavoured, but fruitlessly, to move the head; the force was gradually increased to the utmost I could exert, still without effect. The crotchet was then changed from the left to the right side of the pelvis, and fastened on the frontal bone: this was brought into the brim with less difficulty. The crotchet was again changed to its former position, and the occiput then moved; at length, by one powerful effort the head was brought through the brim; its descent through the cavity, and its expulsion, did not occupy five minutes. The shoulders passed in the transverse measurement, and were more easily brought down. She was delivered at a quarter past nine o'clock.

Steady pressure was applied to the fundus uteri, and the placenta expelled in about ten minutes, without any hæmorrhage, although the uterus felt large and spongy. She was carefully bandaged, the soiled clothes removed, and the bed made more comfortable for her.

In about a quarter of an hour afterwards, she awoke very quietly, looked round, recognised me, and was perfectly unconscious of anything that had occurred. She said she had no pain then, but was fully under the impression that her trial was before her, when we told her that all was over. She looked about incredulously; and as each of the gentlemen present were leaving the room, she became quite alarmed, imagining that we were about to desert her. When she was at length convinced of the fact, her delight may be readily conceived. She describes the effect of chloroform as causing a much more refreshing sleep than she had previously enjoyed, so much so, that when first spoken to, she folt annoyed at being disturbed.

Immediately after delivery, the pulse was 136; as she awoke, it rose to 150 , but soon resumed its original rate of 120 . She was ordered ten grains of Dover's powder.

26 th.-She slept well during the night; pulse 115; no pain over the uterus or abdomen; urine retained, which was drawn off with much relief; she had some headach and cough during the day, (she had influenza before labour.) In the evening her pulse increased to 135 , which was attributed to the excitement of seeing a number of friends, who crowded her room during the day to satisfy their curiosity.

27 th.-She is in every respect improved; pulse 100 . In the evening, 84 .

29 th--Pulse 78 ; no pain of any kind anywhere; the wrine has been drawn off daily, and, with this exception, not the slightest troublesome symptom has occurred to interrupt her recovery, which, in her mind, forms a strong contrast to her previous confinement, from which she did not completely recover for some months. 